\title{
ALGUNAS CONSIDERACIONES SOBRE LA IMPORTANCIA FORMATIVA DEL PENSAMIENTO DE VICO PARA LOS ESTUDIANTES QUE SE ACERCAN POR PRIMERA VEZ AL ESTUDIO DE SU FILOSOFÍA
}

\author{
Paolo Fabiani \\ (Universidad de Florencia)
}

\begin{abstract}
RESUMEN: Este artículo está idealmente dirigido a aquellos que ya conocen un poco la filosofía y están decidiendo en qué sector de la misma profundizar, o, por el contrario, a eruditos expertos que decidan cambiar de sector y acercarse a la filosofía de Giambattista Vico. Según este filósofo, el pensamiento humano nació como pensar por mitos, a través de mitos. Al principio, el pensamiento humano era exclusivamente un pensamiento mitológico sin ningún término de comparación, confrontación o contrapeso con el pensamiento "racional" y abstracto que, de hecho, aún no existía. El mito lo llenaba todo o, mejor aún, la imaginación primitiva lo llenaba todo con el mito. Este es un principio, pero también un presupuesto de la filosofía contenida en la Scienza nuova. En mi opinión, el estudio de Vico debería partir de este concepto fundamental.
\end{abstract}

Palabras ClaVE: Vico, $350^{\circ}$ Aniversario, mito, imaginación, P. Fabiani.

\section{Some considerations about the educational importance of Vico's thought for students that encounter his philosophy for the first time}

ABSTRACT: This article is ideally aimed at those who already know a little about philosophy and are deciding which part of it to focus on, or, on the contrary, expert scholars who are considering whether to change their area, and to approach the philosophy of Giambattista Vico. According to this philosopher, human thought was born thinking by myths, through myths. At first, human thought was exclusively mythological, and not in contrast, confrontation or counterweight with any kind of "rational" or abstract thought, which, in fact, did not yet exist. The myth filled everything —or shall we rather say, the primitive imagination filled everything with myth. This is a principle, but also a presupposition of the philosophy contained in the Scienza nuova. In my opinion, Vico's study should start from this fundamental concept.

KEYWORDS: Vico, $350^{\text {th }}$ Anniversary, myth, imagination, pedagogy, P. Fabiani.

\section{Alcune considerazioni sull'importanza formativa del pensiero di Vico per gli studenti che si avvicinano per la prima volta allo studio della filosofia}

RIASSUNTO: Questo articolo è idealmente rivolto a chi ha già una qualche conoscenza di filosofia e deve decidere quale settore approfondire di essa, o, al contrario, a studiosi eruditi che decidono di cambiare settore e avvicinarsi alla filosofia di Giambattista Vico. Secondo questo filosofo, il pensiero umano nasce come pensiero dai miti, attraverso i miti. All'inizio, il pensiero umano era esclusivamente un pensiero mitologico senza alcun termine di paragone, confronto o contrappeso con il pensiero "razionale" e astratto che, di fatto, non esisteva ancora. Il mito riempiva tutto o, meglio ancora, l'immaginazione primitiva riempiva tutto di miti. Questo è un principio, ma anche un presupposto della filosofia contenuta nella Scienza nuova. A mio parere, lo studio di Vico dovrebbe partire da questo concetto fondamentale.

PARole Chiave: Vico, $350^{\circ}$ Anniversario, mito, imaginazione, P. Fabiani.

Este artículo responde a una invitación expresa por parte de la Dirección de la Revista para este volumen especial por el $350^{\circ}$ Aniversario del nacimiento de G. Vico, habiendo superado los criterios de valoración y del proceso de aceptación. 


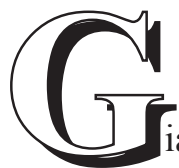

iambattista Vico fue un innovador y, como todos los innovadores, tuvo que pagar prenda al destino. Una cierta desgracia que siempre lo ha acompañado en su difícil y casi mísera existencia, una ingenuidad congénita y nunca completamente superada con el esfuerzo de la inteligencia y de la meditación; los eventos que fatalmente se le volvieron en contra, ralentizándolo, bloqueándolo $\mathrm{y}$, a veces, haciéndolo retroceder y perder tiempo. El tiempo, el único elemento importante en la vida de toda persona que verdaderamente desee desarrollar su propio espíritu (como se decía antes), la única cosa que verdaderamente cuenta cuando se tiene un objetivo existencial a cumplir. Este fue su principal problema y no es casualidad que el año de publicación de la versión "definitiva" de la Scienza nuova (a cargo de su hijo Gennaro) sea el mismo de su muerte. Por contra, como todos los innovadores, tenía una fuerza de carácter excepcional, una admirable perseverancia en llevar a buen fin la tarea que el destino le había asignado o de la cual, platónicamente, él se había hecho "voluntariamente" cargo en una difícil elección prenatal. Estos, en resumen, son los datos biográficos que motivan mi admiración por el hombre Giambattista Vico. Pero existen, sobre todo, también algunas razones teóricas que siempre me han hecho preferir su pensamiento.

Los grandes filósofos se dividen, grosso modo, en dos categorías: los innovadores y los "sistematizadores". Los que crean y los que ordenan. Solo por dar algunos ejemplos: Descartes y Vico forman parte de los innovadores; Kant, Santo Tomás, Spinoza (y también los empiristas como Locke, Bacon, los materialistas como Hobbes o los escépticos como Hume) forman parte de aquellos que ordenan, aclaran, revelan; estos últimos son, en definitiva, todos los que crean sistemas (e incluso los escépticos, a su manera, lo hacen). Desde un punto de vista "viquiano", los escépticos y materialistas son ordenadores del sentido común. A las personas les gustan mucho más los sistemas que las innovaciones. Los sistemas, por su naturaleza intrínseca, tienden al orden, y las personas cuando se encuentran frente a algo ya ordenado, lo aceptan más fácilmente. Esto de hecho requiere menos esfuerzo intelectual y especulativo. Los innovadores a menudo son comparados y confrontados con los "sistematizadores": de hecho, Vico de vez en cuando, ha sido comparado con Kant, con Hegel, con los estructuralistas, con los empiristas, con Spinoza, con Hobbes, con los iusnaturalistas, etcétera. Es el espíritu de quien no comprende la innovación al operar en esta reductio, impropia, en cuanto parcial, porque entender la innovación, allí donde se manifieste, también es una operación compleja. Ciertamente, ser innovadores es aún más difícil y, a fin de cuentas, no es una elección del individuo, sino una tarea asignada por la Providencia o, si tiene una visión más secular, por el destino. Al final, siempre es una cuestión de comprensión y de 
aceptación. A menudo, en efecto, el problema no es que las personas no comprendan las nuevas ideas y las nuevas teorías; la verdad es que les interesa fingir no haberlas entendido o, lo que es peor, decidir ignorarlas. De ello se sigue la tendencia general, generalizada, obligada, a contraponer a la innovación una obtusa reticencia que lleva a no tomar en consideración o, por el contrario, desemboca en una clara intención de despreciar. Es un sentimiento que lleva a una "cuasi-conciencia", pero que nunca alcanza un reconocimiento explícito, claro y aceptado de la innovación. Se prefiere por envidia, interés personal o por un sentimiento de coherencia con lo que se ha aprendido y aceptado (y no se trata de un problema relacionado con un solo comentarista, con un solo intelectual, sino generalizado a toda la categoría de los estudiosos), ignorar al innovador y el mensaje que sus obras traen como regalo. La "casta" (como está de moda decir ahora) de los intelectuales a menudo se escuda en su propio bagaje de conocimientos consolidados y a ello se atiene. El concepto de "boria dei dotti" tiene, prima facie, también este significado, aunque en el marco viquiano asuma, sobre todo, otra -y más importante- situación teórica. E ignorar la invención del innovador siempre conviene, tanto más cuando, en cuanto él murió, cuando ya no la podría reivindicar, la comunidad de los doctos podría reciclarla fácil y ampliamente. Esto es lo que le sucedió a Vico y a otros como él.

Pero hay otros dos elementos a considerar. Primero, los innovadores también crean sistemas a pesar de ellos mismos. Así como todo "sistematizador" (el que crea un sistema filosófico y hace de tal sistema el eje de su teoría) es, al menos en parte, también un innovador; banalmente: es una cuestión de proporciones. El hecho es que, en los innovadores, la estructura del sistema no siempre es evidente. En filosofía, sobre todo, los sistemas innovadores proceden mediante cadenas de principios, de ideas, de axiomas jerárquicamente dispuestos, pero en los que los anillos de conexión entre los diversos "ejes latitudinales" no siempre son evidentes. No se comprenden las consecuencias de las afirmaciones hechas: el marco del sistema filosófico debe ser descubierto por el lector, no es "palpable" de por sí, ni puede darlo el autor si no es a costa de simplificar excesivamente. Simplificación que, además, ha intentado hacer el mismo Vico en la imagen mnemotécnica llamada dipintura puesta en el "umbral" de su obra principal y que solo puede ser bien entendida si se conocen las bases de las mnemotécnicas. En las filosofías de la innovación, por lo tanto, el esquema está siempre presente, pero debe descubrirse, no es claramente identificable, se oculta bajo la superficie de las teorías. Además -pero no solo- en este sentido debería interpretarse la famosa frase de Descartes "larvatus prodeo": el sistema innovador procede como un río magmático subterráneo desde las laderas del volcán de la innovación. La invención siempre crea un sistema, pero un sistema nuevo y, por lo tanto, difícil de reconocer precisamente porque es diferente de lo que ya existe, es algo aún no "catalogado". El sistema es, en un cierto sentido - malinterpretado por los estructuralistas, por un lado, y por los deconstruc- 
tivistas por el otro-, recompuesto o, mejor dicho, "re-combinado". Las palabras no revelan, como en el caso de los "ingenieros de sistemas", el "marco teórico" de la obra: debe ser el lector -al descubrirlo primero y recomponiéndolo después- quien le confiera una forma no "cuadrada" (por mantener la metáfora), sino más bien triangular, piramidal. Se debe aplicar el principio interpretativo de la reductio ad unum, de forma tal que proporcione una teoría compleja y, casi, completa (es decir, omnicomprensiva), como una Filosofía madura (con F mayúscula) debe ser capaz de manifestarse. Pero esta operación es dificilísima, tan es así que los principios fundamentales de la filosofía de Vico, así como los de la filosofía de Descartes, son a menudo mal entendidos, no vistos como lo que realmente son, incluso mal interpretados por lectores competentes y exigentes. De hecho $-\mathrm{y}$ este es un elemento más para comprender a un innovador-, se debe tener una mente capaz de interpretar las "mutaciones", las "transformaciones" que la innovación comporta, y tampoco esta "cualidad" es tan fácil de poseer. En un cierto sentido, y se me ocurre otra metáfora (que quizás no sea solo una metáfora), es una cuestión de "gracia". Se debe recibir el don de la comprensión y este solo puede "alimentarse" mediante un enorme esfuerzo. Resulta fácil a quien está provisto de ello por naturaleza (o "gracia" justamente), pero para los demás es casi prohibitivo, a menos que se encuentre un maestro verdaderamente dotado que, con los años (cualquier seminario universitario ciertamente no basta), indique el camino correcto. Pero ¿no es quizá también esto una señal de la Providencia?

Finalmente, otro gran riesgo que se corre acercándose al pensamiento de Vico es el de confiar demasiado en la crítica historiográfica y filosófico-historiográfica o, mejor, en una versión "simplificada", trivializada de la crítica. Cuando empecé a estudiar a Vico había unos lugares comunes convertidos en cuestiones esenciales: 1) el italiano de Vico es incomprensible, corrompido y casi dialectal (aunque esto no es absolutamente cierto: la Scienza nuova está escrita exclusivamente en italiano, no en el dialecto, y la dificultad de su italiano no es sintáctica ni léxica, sino más bien estilística y lógica); 2) Vico refuta la filosofía cartesiana (esto es un malentendido y un error al mismo tiempo). El rechazo del método cartesiano por parte de Vico es declarado, pero no significa nada. En la primera mitad del siglo XVIII, todos criticaban el método cartesiano y nadie lo utilizaba. El mismo Descartes no lo había seguido -excepto de manera marginal- en la construcción de sus principales teorías científicas. Vico rechaza la prohibición del valor de verdad de la historia por parte de Descartes, como es sabido, pero acepta -como es mucho menos conocido- el subjetivismo cartesiano o, más precisamente, la perspectiva subjetivista en la filosofía, como fue aceptada lato sensu por Spinoza, Leibniz, Kant, Husserl, etc. Incluidos también los críticos empiristas y escépticos -Locke, Hume, Berkeley-, los cuales, más allá de proclamas, nunca han estado en situación de superarla. 3) Vico en su tiempo era desconocido y su ciudad, Nápoles, estaba al margen de la cultura de la 
época (ciertamente era menos conocido que los otros grandes filósofos coetáneos, pero su valor como estudioso era muy conocido y, en cuanto a cultura, la Nápoles de principios del XVIII, incluso con todos sus conocidos problemas atávicos, era un centro cultural de importancia primordial no solo en Italia sino también a nivel europeo). Además de estos aspectos, hay otros que yo denomino de la omisión. Es decir: la mayor parte de las críticas (aunque debe admitirse que las cosas están cambiando gradualmente, pero con dificultad, en las últimas décadas) relega la cuestión de las implicaciones metafísicas de la mitología a los márgenes del discurso viquiano, cuando la mayoría de las "palabras" escritas por Vico en sus obras principales van precisamente en esta dirección. Insisto: no la simple mitología, sino el análisis de las implicaciones teóricas que proporciona la interpretación viquiana de los mitos. Se considera, por poner un ejemplo, el principio del verum factum separado de la cuestión del nacimiento de las naciones, como si fuese un principio científico nacido de la mente de un epistemólogo del siglo XX. Suerte paralela corrió la concepción viquiana de la historia: se la entendió como una teoría en sí misma, ajena a la reconstrucción de la "mente primitiva" y de la "mente" en general que Vico había desarrollado sobre todo (pero no solo) en la Scienza nuova.

En definitiva, si os acercáis a la filosofía de Vico, y preferís el estudio de esta a la de otro gran pensador, lo que debéis hacer es tratar de establecer objetivos precisos para la identificación de "claves interpretativas" viquianas de la realidad bien claras. Si tenéis celada la intención de escribir comentarios como si fuesen post en Facebook, tanto vale un autor como otro. Si, por el contrario, os gusta la filosofía por la filosofía, entonces Vico tiene muchos elementos de originalidad que verdaderamente pueden haceros dar un paso adelante en la comprensión del pensamiento filosófico tout court. Desgraciadamente, para comprender a Vico se debe comenzar leyendo también los comentarios, dado que el estilo de la Scienza nuova es un poco "arduo" y poco habitual para una lectura nocturna. Mirad, si en la universidad os han dado una línea a seguir, lo que debéis hacer es leer sobre todo a aquellos comentaristas que no están en esa línea. Leed siempre a aquellos que piensen de manera diferente a la vuestra o a la forma en que os han dicho que se debe pensar. Cada cual tiene su modo de entender las cosas, y cada uno de estos es siempre parcial, incluso el nuestro lo es y seguirá siéndolo, por lo que la única manera de progresar verdaderamente es profundizar en las perspectivas diferentes a la nuestra. No se trata de la simple lectura crítica para ampliar los horizontes intelectuales: debe ser un ejercicio de maduración para compensar una tendencia natural a la confirmación de las propias opiniones. Opiniones que entonces, tal vez, también pueden ser confirmadas, pero que es bueno que previamente sean "liberadas" al menos del material ideológico más burdo. La filosofía de Vico es, en este sentido, un excelente instrumento de crecimiento personal. Debido a la complejidad estilística y la lógica de la Scienza nuova, a las peculiaridades de las temáticas abordadas, a la aparente no sistematici- 
dad del marco global de toda la obra de Vico, es posible "crear" un nuevo y autónomo pensamiento partiendo precisamente de ella. Es cuanto menos singular, aunque muy explicable, darse cuenta de cómo pocos han aprovechado esta oportunidad.

¿Existe una "prueba del 9" para verificar si nuestro trabajo de historiadores de la filosofía conduce a una verdadera maduración filosófica o, por el contrario, nos relega a una inútil tarea de verbalizadores del pensamiento ajeno? Sí, y consiste esencialmente en verificar si, a lo largo del camino, se piensan cosas nuevas y se redefine el propósito y el objetivo que queríamos alcanzar. Si escribiendo y comentando surgen de nuestra mente ideas nuevas, pensamientos en los cuales previamente no habíamos pensado; si, al final, el marco teórico que habíamos pintado es diferente (al menos en parte) desde el boceto que habíamos trazado al principio, entonces estamos en el camino correcto. Si, al contrario, el arte menor del comentario y el estudio, solo confirman la tesis inicial, entonces nuestro trabajo es probablemente solo un inútil ejercicio de estilo. El estudio de un innovador como Vico debe, necesariamente, 1levar más allá de la filosofía de Vico e incluso más allá de nuestras propias tesis. Debe, dicho de otro modo, hacernos expresar nuevos conceptos, ideas, reflexiones. El pensamiento de Vico predispone a esta tarea mayéutica por parte del comentarista. Obviamente, esto significa que se puede afirmar todo y lo contrario de todo partiendo de la filosofía viquiana. La teoría de los universales fantásticos no justifica, por ejemplo, la tesis según la cual Vico creía en los ovnis. Sin embargo, muchas interpretaciones del pensamiento viquiano (y no solo viquiano) tienen esta forma lógica: se parte de un presupuesto y desde allí se acomoda, yuxtaponiendo de manera forzada y forzosa, todo lo demás. Se pasa demasiado tiempo comentando, poco estudiando, y casi ninguno reflexionando. Y esto también es un problema, porque los libros a menudo ni siquiera se leen, se consultan solamente. Pero si queremos hacer filosofía debemos reflexionar, y para reflexionar hay que leer con atención los resultados de los que se han enfrentado a las mismas cuestiones antes que nosotros. Mejor leer poco y con atención que no mucho pero distraídamente.

Que quede bien claro: una reorganización del material debe existir, pero no debe ser un plegamiento, una distorsión y una banalización de los conceptos. Mi personal "prueba del 9" es esta: la reductio ad unum. Cread una jerarquía de tesis, ideas, conceptos que hayáis recabado del estudio del pensamiento de Vico. Luego disponedlos jerárquicamente. En el vértice debe haber una y solo una idea. De ella deben descender todas las demás e, incluso en la última de la pirámide, debéis tener evidencia (es decir, una visión clara) del vínculo que la une a la idea del vértice. Tenéis que ir en busca de las semejanzas y proceder por similitudes. Después haced la operación contraria, buscad para cada específica teoría, tesis, explicación, su unicum, eso que la caracteriza. En este caso, debéis saber circunscribir, identificar el particular distintivo y proceder por separación, distinción. Soy muy consciente de que esta forma de proceder, en su aparente simplicidad, tiene milenios; es suficien- 
te leer a Platón y Aristóteles para aprenderlo. Pero, y aquí está mi crítica, no hay rastros de ella en los estudios sectoriales que en enormes cantidades se publican año tras año. Si no obráis de este modo, os arriesgáis a poner todas las ideas en el mismo plano -y nunca lo están-, y de perder el sentido profundo de un pensamiento. Por lo que respecta a la filosofía de Vico, en el vértice de la pirámide yo he colocado la teoría de los universales fantásticos y, específicamente, el mito de Júpiter. Si se comprende profundamente esta teoría, después se nota cómo a partir de ella todas las demás tesis, explicaciones, interpretaciones, etc., hechas por Vico asumen su lógica y consecuente luz. Soy consciente de que estas afirmaciones mías se prestan a toda una serie de críticas, pero para mí no es importante ser criticado, sino exponer algo que creo, al menos un poco, útil. La concepción de la historia, de la mente primitiva y no solo, la teoría del verum factum, etc., encuentran así su lugar correcto. En seguida me puse a considerar las diferencias que existen entre las diversas fases históricas, de la evolución de la mente, la proliferación de los mitos, los cambios en la sociedad y muchas otras "cosas" ("cosas" en sentido mnemotécnico) que explicó Vico. Parafraseando -aunque forzando la comparación-el criterio aristotélico de la definición, se debe proceder por género próximo (la reductio ad unum que, en mi caso, es el universal fantástico de Júpiter), y diferencia específica (lo que distingue, por ejemplo, el mito de Juno del de Júpiter, el cambio que el mismo mito de Júpiter asume en las diversas fases de la historia, la relación entre la mitología y el verum factum, etc.).

Vico supo construir una filosofía extremadamente vasta y compleja capaz de remitir a unos pocos principios y luego a uno solamente, muchas temáticas diferentes. Su reflexión se mueve libremente de la metafísica a la historiografía, a la antropología, a la gnoseología, a la estética, a la lingüística, a la moral, y sentó las bases para una teoría comparada sobre la poesía, la mitología, etc. La suya es, en cierto sentido, una filosofía "completa" ( $i \sin$ embargo, no acabada!), pero dicha plenitud le viene de una "organización en cascada" de principios, el primero de los cuales es -en mi opinión- precisamente el universal fantástico de Júpiter. El hombre en cuanto animal se convirtió en un ser pensante en el momento en que, en lugar de reaccionar ante el ambiente de manera instintiva, objetivó en una imagen mental (las nubes de un temporal que avanza y asusta con sus truenos y rayos) su miedo instintivo hacia lo que es grande y maravilloso. Este es el primer pensamiento humano: no el pensamiento de sí mismo, no el pensamiento de algo que él hace, sino el pensamiento de una deidad que le habla. Y esta deidad no es algo o alguien que está detrás del trueno, el rayo y el temporal. Júpiter es esas nubes y sus palabras son esos truenos y esos destellos. El primer pensamiento es, por tanto, un hablar entre sí convencidos de hablar con otro (la deidad), un otro presente solo en la mente, pero que se cree "vivo" en el cielo (cielo que, sin embargo, no se reconoce como tal: el cielo no existe, solo existe Júpiter y esto se debe a que la imagina- 
ción primitiva aún no es capaz de distinguir, dividir, las imágenes entre sí e incluso los conceptos frente a las imágenes: todos estos elementos están como fundidos en el magma primordial de la fantasía). El primer pensamiento es, por lo tanto, pensamiento del otro y pensamiento de la divinidad. A partir de ese momento, el hombre deja de ser solo un animal y se convierte en un poeta teólogo, es decir, en un creador de significados. Empieza a crear usos y costumbres basados en sus propias fantasías, es decir, en sus propios pensamientos. Luego comienza a dividir sus propios pensamientos, es decir, a distinguirlos unos de otros y, al hacerlo, comienza a producir nuevo pensamiento. Todo lo que encontrará en su vida será al inicio una manifestación de Júpiter, con el tiempo, cada cosa asumirá su significado específico. Esto nos llevará a ver a Júpiter en todas las cosas y, con el tiempo, a distinguir cada cosa frente a Júpiter. De ahí la abstracción mental, la escisión entre significado y significante, la proliferación de deidades, etc. Lo que el hombre hará será en el nombre de y en honor a Júpiter. Los usos y costumbres como el matrimonio, las primeras sociedades reguladas por la ley divina, darán a los primeros poetas teólogos, a los primeros héroes -es decir, a los primeros hombres pensantes- una notable ventaja sobre los demás. Los otros, los llamados fámulos, son los que continúan viviendo de una manera gregaria, a pesar de que las primeras sociedades "humanas" ya se hayan formado; en estas buscarán refugio ante los peligros de la naturaleza pidiendo asilo en las familias de los héroes, es decir, de los hombres pensantes en cuanto poetas teólogos (es decir, creadores de la divinidad... con la imaginación). Asilo que se les concederá, pero al precio de su sometimiento. De ahí la subdivisión en clases, por una parte, los poetas teólogos se convertirán en "nobles", iluminados por el pensamiento y, por esta razón, en cabezas de familia; por otra parte, los fámulos, todavía poco más que animales, sojuzgados y esclavizados. La "Historia" como nueva ciencia, se inicia aquí: a partir de considerar lo que el hombre realmente hizo, inventó. Y el hombre creó, inventó, su propio "mundo" de pensamiento, su propio mundo de imágenes, de fantasías. Pero solo a través de esta interposición él pudo darle un significado diferente a la realidad material, un significado distinto del biológico que le indicaba -imponía- el simple instinto.

El hombre ha hecho su propia historia, pero esta es el resultado de otra creación humana: la sociedad y esta "invención" no hubiera sido posible sin la imaginación mitológica. Además, el desarrollo del pensamiento y el lenguaje asume una connotación "sociológica": es a partir de la convivencia entre poetas teólogos "iluminados" por el pensamiento y fámulos como se lleva a cabo la "escisión", lingüística y lógica al mismo tiempo, entre el significante y el significado. Viviendo con los héroes, también los fámulos hablaban su (de los héroes) lengua "divina", pero no comprendían su significado. Para los fámulos, el uso de la lengua había finalizado (como para nosotros ahora) con un uso instrumental y cotidiano, casi pragmático, podría decirse. Esta sintética, simplificada y, lo reconozco, en ciertos momentos 
incluso inexacta exposición podría continuar, pero, incluso estas últimas reflexiones, no son -como una gran parte de la reflexión crítica sobre Vico querría- un manifiesto del pensamiento pragmatista o empirista. El verum ipsum factum, lo que verdaderamente el hombre ha hecho es el "producto", las consecuencias de su propio pensamiento, pero no de su pensamiento racional (en las sociedades paganas), sino de su pensamiento fantasioso. El principio del verum factum, según el cual solo se puede conocer lo que se hace, se aplica en primer lugar a la mitología. El hombre (a excepción del pueblo elegido iluminado por la palabra de Dios a través de las Sagradas Escrituras) creó sus propias fantasías. Estas fueron su primera creación, su primera invención: el pensamiento nace como fantástico, es un pensamiento por mitos. Verum ipsum factum -en el contexto viquiano- significa que el hombre crea ilusiones. En cambio, se quiere también forzar este principio en un sentido "materialista" y "pragmatista". No estoy diciendo que no sea un principio que pueda ser aceptado por un materialista o un pragmatista; estoy afirmando que todo esto no tiene nada que ver con la filosofía de Vico. En la Scienza nuova se habla principalmente de mitos, y hablar de mitos significa, esencialmente, hablar del pensamiento fantástico. Si el verum factum puede aplicarse a la historia es solamente porque la historia se compone de "gestas" realizadas por humanos y la "motivación", el impulso mental que llevó a los seres humanos para hacer eso, es su pensamiento fantástico, su pensar mediante mitos. Es cuanto menos notable que los mayores críticos (y muchos otros a seguir) del pensamiento viquiano no se hayan dado cuenta. Paradójicamente, quien pretende hacer una lectura "ortodoxa", "objetiva" del pensamiento viquiano, niega la evidencia; parece no darse cuenta de que Vico habla esencialmente de mitología y, por lo tanto, del pensamiento humano como un pensamiento fantástico. Todas las demás teorías, en el discurso viquiano, vienen después y dependen de ello (es decir, del análisis y de la comprensión del pensamiento fantástico).

Por ende, recomiendo a los jóvenes que se apasionan por Vico que emprendan este camino de estudio desde la vertiente del pensamiento fantástico. No solo es el más "divertido", sino que también es el más correcto filológicamente y desde el punto de vista historiográfico. De este modo creo haber comprendido que Vico -más allá de algunos errores suyos macroscópicos y de un lenguaje construido en teoría por los resultados estilísticamente intrincados- fue no solo un gran innovador, sino también un "fantasioso ingeniero de sistemas", un filósofo que supo crear un sistema doctrinal original, innovador, a veces incluso extravagante, pero, a su manera, coherente.

[Trad. del italiano por María José Rebollo Espinosa]

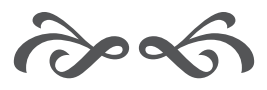


<smiles>[As]</smiles> 